\title{
O circo no cenário educacional no Brasil e países da América Latina $^{1}$
}

\section{The circus in the educational scenario of Brazil and Latin American countries}

Bortoleto, Marco Antonio Coelho, Barragán, Teresa Ontañón, \& Silva, Erminia (Orgs.). (2016). Circo: horizontes educativos. Campinas: Autores Associados.

Ademir Faria Pires (i)

Jonas Spaciari Matioli (ii)

Ieda Parra Barbosa Rinaldi (iii)

\footnotetext{
(i) Universidade Estadual de Maringá - UEM, Maringá, PR, Brasil. https:/ /orcid.org/0000-0003-41642942, afariapires@gmail.com.

(i) Universidade Estadual de Maringá - UEM, Maringá, PR, Brasil. https://orcid.org/0000-0002-61645780, jonasspaciarimatioli@gmail.com.

(iii) Universidade Estadual de Maringá - UEM, Maringá, PR, Brasil. https://orcid.org/0000-0003-12587155, parrarinaldi@hotmail.com.
}

\begin{tabular}{l}
\hline Resumo: \\
Esta resenha visa apresentar e discutir a obra Circo: horizontes educativos, de Marco \\
Bortoleto, Teresa Barragán e Erminia Silva, que se propõe a apresentar horizontes \\
educativos do e no circo. O livro aborda uma temática pouco tratada no meio \\
acadêmico, tornando-se, assim, relevante, especialmente no tocante aos aspectos \\
educacionais. Ao longo dos 13 capítulos, são apresentadas histórias de vida e relatos \\
de experiência acerca do circo em diferentes contextos, nacionais e internacionais, \\
formais e informais, tratando das suas inúmeras possibilidades e viabilizando o \\
entendimento deste objeto como um fenômeno histórico e cultural. \\
Palavras-chave: circo, experiências formativas, formação profissional
\end{tabular}

${ }^{1}$ Normalização, preparação e revisão textual: Douglas Mattos (Tikinet) - revisao@tikinet.com.br 


\title{
pro.posıções
}

$e$-ISSN 1980-6248

http://dx.doi.org/10.1590/1980-6248-2019-0050

\begin{abstract}
:
This review aims to present and discuss the work Circus: educational horizons of Marco Bortoleto, Teresa Barragán and Erminia Silva, which proposes to present educational prospects within the circus. The book approaches a theme that is not very well treated in the academic field, making it relevant, especially in relation to educational aspects. Throughout the thirteen chapters are presented life stories and experience reports about the circus in different contexts, national and international, formal and informal, dealing with its innumerable possibilities, making possible the understanding of this object as an bistorical and cultural phenomenon.
\end{abstract}

Keywords: circus, formative experiences, professional formation

O livro foi organizado por Marco Bortoleto, livre-docente na Universidade Estadual de Campinas (Unicamp) e coordenador do Grupo Circus, Teresa Ontañón Barragán, doutora em Educação Física (EF) pela Unicamp, e Erminia Silva, historiadora do circo e coordenadora do Grupo Circus. A obra obteve financiamento da Fundação Nacional de Artes (Funarte) e do Ministério da Cultura, com o projeto contemplado pelo Prêmio Funarte Caixa Carequinha de Estímulo ao Circo 2014.

O livro Circo: horizontes educativos destaca-se por apresentar a diversidade do circo na América Latina e Europa, abordando um objeto incipiente na literatura. A obra é composta por 13 capítulos, construídos por autores de diversos países e culturas, possibilitando uma compreensão mais ampla do circo, que hoje está presente em novos lugares, espaços e âmbitos, projetando novas finalidades, práticas, usos e apropriações.

O primeiro capítulo, "Aprendizes permanentes: circenses e a construção da produção do conhecimento no processo histórico", de Erminia Silva, é um estudo de revisão que aborda o contexto do circo. Em seu texto, Silva destaca que os circenses são pesquisadores e historiadores de seu próprio fazer e de suas experiências artísticas, cada qual com sua metodologia e campos teóricos. É levantada a discussão sobre a validade dessas produções, pois não recebem o mesmo prestígio e reconhecimento que outras produções reconhecidas como “científicas". A discussão proposta por Silva perpassa os principais acontecimentos sobre a formação e a produção do conhecimento circense no Brasil, da transmissão oral/familiar até a formação por meio das escolas de circo e em cursos de Ensino Superior, bem como os problemas enfrentados no âmbito político. 


\section{pro.posições}

http://dx.doi.org/10.1590/1980-6248-2019-0050

\section{$e$-ISSN 1980-6248}

O segundo capítulo, "O circo e a formação em Artes Cênicas”, de Mario Bolognesi, busca verificar as contribuições das artes circenses (AC) para a formação profissional (FP) em Artes Cênicas, por meio de uma experiência no projeto de extensão universitária Circo da Barra no Instituto de Artes da Universidade Estadual Paulista. Bolognesi enfatiza que a busca pela formação em circo cresceu nos últimos anos, levando à inclusão de disciplinas circenses em currículos de cursos de Artes Cênicas pelo Brasil. O autor relata vivências do Laboratório de Artes Circenses, ressaltando o trabalho de formação realizado pelo grupo. Uma experiência realizada por alunos de iniciação científica é mencionada, afirmando-se que, por meio desta, foram constatadas as contribuições das AC para o profissional de Artes Cênicas.

O terceiro capítulo, "Escola Nacional de Circo: desafios na gestão de um espaço cultural público de formação profissional", de Zezo Oliveira, apresenta reflexões sobre a Escola Nacional de Circo. Oliveira buscou construir um olhar distanciado, abordando diferentes processos de formação em artes e dos pensamentos desenvolvidos por estudiosos da educação e da formação social. A partir de sua visão, o autor abre um debate sobre a escola e o seu labor pedagógico, sem impedir novas reflexões. Descrevendo alguns desafios da gestão em um espaço público de FP em circo, Oliveira procura ampliar o conceito de formação em circo para além das instituições tradicionais de ensino.

No quarto capítulo, "Notas sobre a formação circense no Brasil: do circo de lona às escolas especializadas", de Rodrigo Duprat, levantam-se discussões sobre a maneira como o conhecimento das AC era transmitido no interior das famílias até o surgimento de uma nova possibilidade de formação com as escolas especializadas em circo, na Rússia. Duprat narra como a formação e a transmissão do conhecimento circense aconteceu no Brasil e destaca que o acesso aos saberes circenses e os novos modelos de formação propiciaram a popularização do circo como conhecimento que pode ser vivenciado por qualquer pessoa. Nesse ponto o autor enfatiza dois grandes grupos de formação: a vivência e a FP.

O quinto capítulo, "La formación del artista circense en Argentina: una historia de revalorización, innovación y desafío", de Julieta Infantino, aborda um pouco da história de uma arte que, na Argentina, foi desvalorizada como uma arte menor, tendo seu desenvolvimento silenciado. A diversidade das trajetórias e perspectivas educativas que se desenvolveram contemporaneamente no Brasil e no mundo são discutidas, levantando dados e reflexões de mais de 15 anos de investigação no campo das AC. As histórias compartilhadas neste capítulo 


\section{pro.posıções}

http://dx.doi.org/10.1590/1980-6248-2019-0050

$e$-ISSN 1980-6248

são de cunho antropológico e narram a história do ensino do circo na Argentina, despertando um debate sobre o Estado e as políticas públicas de fomento à educação circense.

O sexto capítulo, de Donald Lehn, "La formación artística en circo: estrategias de la Federación Europea de Escuelas de Circo Profesionales (Fedec)", apresenta a relevância internacional que o circo possui na Espanha. $\mathrm{O}$ autor faz um apanhado histórico do circo no país e em Madrid. Assim como nos demais capítulos da obra, Lehn denota o papel da FP para as AC, discutindo as competências e características necessárias ao profissional da área. Apresenta-se um estudo realizado pela Fedec, mostrando como essas competências e características são importantes para os artistas circenses. São tratadas as estratégias desenvolvidas na Fedec, divididas em três níveis: para diretores pedagógicos e artísticos, para os professores e para os alunos.

O sétimo capítulo, "La Tarumba: circo peruano", de Fernando Villalobos e Geraldine Oshiro, apresenta a contextualização histórica do circo no Peru, destacando a trajetória do La Tarumba desde a sua criação, no ano de 1894, até o projeto de criação da escola profissional de circo. Ressalta-se o esforço desmedido dos integrantes do grupo La Tarumba para o crescimento do projeto até o surgimento da Escola Profissional de Circo Social. Os autores também retratam a Escola Profissional e sua premissa de formar o ser humano, jovens comprometidos com o país. São tratadas as propostas artística e pedagógica, abordando as ações didático-metodológicas, o desenvolvimento do grupo e o crescimento de seu público. É possível perceber a história e criação de um grupo circense e como suas ações tornaram um grupo de artistas numa escola de formação.

O oitavo capítulo, "O circo e sua contribuição para a educação escolar", de Teresa Ontañón Barragán, apresenta as contribuições da aproximação entre a escola e as AC na construção de uma educação que valorize as individualidades, incite o respeito às diferenças, estimule a cooperação e minimize a competitividade. A autora discorre sobre a importância do circo durante a formação escolar e defende a inclusão deste conteúdo na escola, mostrando sua legitimação como conteúdo da EF. A autora explicita a importância do trabalho das dimensões criativa, estética e expressiva com o conteúdo do circo, visto que quando se dá prioridade apenas aos conteúdos técnicos, a prática pedagógica pode se tornar engessada. A formação inicial e continuada é sinalizada como indispensável para o futuro trabalho com os conteúdos circenses, sendo apontados caminhos para seu trabalho na escola. 


\section{pro.posições}

http://dx.doi.org/10.1590/1980-6248-2019-0050

\section{$e$-ISSN 1980-6248}

O nono capítulo, "Novos status para o circo no Centro-Oeste: a Escola de Circo Laheto", de Maneco Maracá e Larissa de Paula, é um relato de experiências que aborda a criação do Circo Laheto, entre as décadas de 1970 e 1980, e seu desenvolvimento ulterior, mencionando os espetáculos já montados pelo grupo do surgimento até o ano de 2016. Um dos destaques para o projeto deste circo-escola é seu objetivo de atender crianças e adolescentes em situação de vulnerabilidade socioeconômica. A concepção de educação defendida pelos autores é pautada na pedagogia de Paulo Freire e, em linhas gerais, percebe-se que este projeto busca atender os objetivos de minimizar as desigualdades e lutar pela infância e adolescência, verificando a importância da implantação de projetos que visem trabalhar a formação humana por meio das AC.

O $10^{\circ}$ capítulo, "A arte como fomentadora do desenvolvimento humano: um estudo com adolescentes em Mogi Mirim/SP”, de Maria Isabel Somme e Maria Rosa Camargo, discute as contribuições das AC a partir de pesquisa realizada com adolescentes participantes de uma organização não governamental na cidade de Mogi Mirim/SP. É possível verificar ao longo do texto que as autoras utilizaram Vygotsky e Guyau como referencial teórico, principalmente para discutir os aspectos relacionados a educação, arte e linguagem, mostrando a relevância do circo para o desenvolvimento destas habilidades. Os elementos referentes à arte são debatidos como formas de criação, que estimulam o processo criativo de crianças e adolescentes. Ao final, as autoras reforçam a importância de se utilizar a arte como forma de despertar a criatividade e a fruição em espaços educacionais, sobretudo a partir das AC.

O $11^{\circ}$ capítulo, "Circo, desenvolvimento e educação infantil", de Ademir De Marco, busca discutir as contribuições que o circo tende a oferecer para o desenvolvimento pleno da criança nas dimensões cognitiva, afetiva, social e motora. São apresentadas as relações do circo com o desenvolvimento infantil por meio de jogos malabarísticos. Para apresentar as contribuições psicológicas e neurológicas, utilizam-se referenciais teóricos do desenvolvimento motor como Maslow e Gesell. O autor discute as contribuições psicológicas provenientes das atividades circenses, elencando o jogo como uma tarefa que contribui para este processo. Os jogos malabarísticos são apontados como um apoio para o desenvolvimento motor em geral, sendo apresentada a possibilidade do trabalho interdisciplinar das AC na escola objetivando o desenvolvimento integral da criança. 


\section{pro.posıções}

http://dx.doi.org/10.1590/1980-6248-2019-0050

\section{$e$-ISSN 1980-6248}

O $12^{\circ}$ capítulo, "As relações humanas na pedagogia do circo social desenvolvidas pela Escola Pernambucana de Circo", de Maria de Fátima Pontes, relata a experiência na Escola Pernambucana de Circo. A autora apresenta a história da escola bem como seu objetivo de promover, por meio das artes e da pedagogia do circo social, a inclusão social de crianças, adolescentes e jovens. São apresentadas atividades estratégicas, desenvolvidas em sua prática com a pedagogia do circo social, tais como a valorização de todos, as aulas de circo e a criação de números. São elencadas, ainda, algumas das recompensas pelos anos de trabalho da escola e comenta-se a parceria realizada com a Trupe Circus. O trabalho realizado pela Escola é considerado como mais um exemplo de trabalho coletivo que visa a formação de crianças e adolescentes carentes, em situação de vulnerabilidade social.

O $13^{\circ}$ capítulo, "As atividades circenses na FEF-UNICAMP: a construção de uma nova área de estudos e pesquisa", de Marco Bortoleto, Rodrigo Duprat e Bruno Tucunduva, apresenta a trajetória das AC na Faculdade de Educação Física (FEF) da Unicamp por meio do ensino, da pesquisa e da extensão desde 1989, quando se iniciaram os trabalhos envolvendo a ginástica e o circo com o Grupo Ginástico Unicamp, chegando até os dias atuais, sendo que o Grupo de Estudo e Pesquisa das Artes Circenses (Circus) foi efetivamente criado no ano de 2006. Narram-se as experiências relacionadas à criação de uma disciplina envolvendo as AC na FEF, bem como as consequências da criação do Grupo Circus para a produção acadêmica na área. Neste capítulo são destacadas as contribuições a partir da criação e do trabalho do grupo no campo da FP, das artes e da produção científica sobre o circo, se fazendo valer o esforço de seus idealizadores e membros.

Esta publicação prova-se relevante, pois o circo é uma temática pouco tratada no meio acadêmico, com uma escassa produção, principalmente no tocante aos aspectos educacionais. Em geral os capítulos apresentam histórias de vida e relatos de experiência sobre o trato deste rico conteúdo em diversos ambientes, o que, num primeiro momento, pode-se considerar repetitivo. Entretanto, por meio destes são indicadas as possibilidades nos diversos contextos/culturas, tais como projetos sociais e ambientes escolares, permitindo ampliar o conhecimento dos leitores acerca deste universo.

Destaca-se que as contribuições das $\mathrm{AC}$ não atingem apenas profissionais restritos a uma área. Por meio da obra, verificamos que estas tendem a promover benefícios para a formação de profissionais da EF, das Artes Cênicas, para crianças e adolescentes, entre outros 


\section{pro.posições}

http://dx.doi.org/10.1590/1980-6248-2019-0050

sujeitos. A obra abarca, portanto, de acordo com os organizadores, diversos lugares, espaços e âmbitos, projetando novas finalidades, usos, apropriações e práticas - pedagógicas, de trabalho e/ou formativas.

O circo vem sendo investigado por pesquisadores de diferentes áreas, como as Artes Cênicas, Arquitetura, Filosofia, Sociologia, Jornalismo, Geografia, Pedagogia e EF, produzindo diferentes e interessantes aproximações com a história. Esse livro, ao abarcar experiências de países da América Latina e Europa e considerar as inúmeras possibilidades apresentadas, mostra que o circo se configura como um campo ainda pouco explorado, sobretudo no Brasil.

Destarte, a obra pode ser de interesse de professores e pesquisadores de diversas áreas do conhecimento que pretendem trabalhar com a temática. Mediante as possibilidades apresentadas, os estudos e relatos podem servir de inspiração e embasamento teórico para novos projetos no âmbito circense, oferecendo subsídios e estímulos para projetos educacionais que demonstram o interesse em trabalhar com o circo e seus "horizontes educativos".

\section{Referências}

Bortoleto, M. A. C., Barragán, T. O., \& Silva, E. (Orgs.). (2016). Circo: horizontes educativos. Campinas: Autores Associados.

Submetido à avaliação em 08 de abril de 2019; aceito para publicação em 13 de maio de 2019. 